\title{
Research on the Art Design of Public Space of Rail Transit
}

\author{
Yulan $\mathrm{Li}^{1, \mathrm{a}}$, Lin Zhang ${ }^{1, \mathrm{~b}}$ \\ ${ }^{1}$ Chengdu Art Vocational College, Chengdu, 611433, China
}

\section{Keywords: Rail transit, Public space, Art design}

\begin{abstract}
Rail transit has become one of the most important means of transportation for urban residents. It is an urgent problem to be studied that how to show the cultural characteristics of the station area and its cities by the artistic design of the public space of the rail transit in our country. In this paper, the basic principles of the art design of the public space of urban rail transit are given, and the key points of the design of the ceiling, the wall and the ground are discussed in order to provide some references for the relative researchers.
\end{abstract}

\section{Introduction}

Along with the city urbanization our country, the rapid growth of population and the number of motor vehicles, traffic load and other phenomena have emerged in the process of the development of big city. The city rail traffic relative to other public transport, with large capacity, high comfort, energy saving and environmental protection and other characteristics, has a significant role in mitigation city traffic pressure and improve travel efficiency and guide the city layout rationalization, promote the city renewal and economic effects on the surrounding land. Therefore, the world's major cities in the development to a certain extent began to adjust the transport structure, and actively develop urban public transport, and vigorously build rail transit, the establishment of integrated transport system. The internal space station building is an interior space created according to the way people travel, to meet the basic requirements of function, need to pay attention to the environmental art design to bring people spiritual values, mainly including: decoration design interior space station ceiling, wall and floor decoration design; public facilities; multiple public art set etc.. Rail transit has become the main and best way for modern urban residents to travel green. With the construction and expanding public space for art design provides the application site, also brought new thinking: how to reflect the regional historical heritage in the public space of city rail traffic, how to express the cultural charm and flavor of the times with the art design language and the way how in the subway public art design in public, aesthetic and so, as planners and designers and the art design education need to face and think about. The art design of public space in urban rail transit can enrich the theoretical research in this field, and can also play a guiding role in practice.

\section{Basic Principles of Art Design of Public Space of Rail Transit}

Complete Functions. Rail transit station is the traffic function as the basic premise, namely the design of public space in the station must first meet the traffic function under the condition of considering environmental art design, to create a good visual image, must not have the order reversed. The first to meet people of station traffic space requirements, on the one hand, to ensure that the internal rail network traffic and transportation and other modes of transportation convenient transfer, orderly organization of inbound and outbound passenger flow, considering effective docking and traffic facilities around and dealing with the relationship between the car and the flow of vehicles; on the other hand according to the people the behavior and other aspects of comprehensive consideration of the layout of the station of indoor and outdoor space, walking space, streamline organization smooth use of reasonable range of traffic, creating traffic space environment quality. Rail transit station public space including space area of ground and underground space area, spatial transformation determines the characteristics of the landscape itself, so changing, need to pay attention to the continuity of the landscape, in order to achieve the visual comfort. One of the most 
important aspects of the environmental design of the station is to facilitate all the traffic behavior of the residents, that is to say, the planning and design of the station space should be as far as possible. The station open, outgoing, contact with the external space smooth, convenient and efficient convergence of people arrived at the station; functional zoning and line arrangement is reasonable and clear, people can quickly reach the various functional areas, improve travel efficiency; the needs of setting service facilities convenient for people, such as toilets, telephone booths, kiosks, ticketing Pavilion facilities concise signage, convenient for people to quickly locate and arrive. Complete function is the first principle of public space design of rail transit.

Visual Beauty. The expansion of the modern media and the enhancement of the learning life consciousness have promoted the improvement of the public aesthetic ability. Therefore, the creation of public space art design should not only lag behind the aesthetic vision of the public, but to some extent, lead the new era and promote the formation of new knowledge. The aesthetic principle is a general rule generally follow the design field, create visual landscape aesthetically and social aesthetic value orientation is the station of public space environment art design to achieve the purpose, but also can add beauty to the city landscape. People in the public space station with visual feeling as the starting point, according to the aesthetic law and the use of different entities in space, through the contrast and unity, symmetry and balance, rhythm and rhyme visual techniques, aspects of processing changes of space form, color, material, on the other hand, with the surrounding buildings and the environment unified, create a rich visual landscape, reflect the beauty and comfort of the public environment, can resonate with the spirit of people's hearts of pleasure. The environmental art design of the public space of the station should take into consideration the harmony and unity with the surrounding environment and the local history and culture. On the one hand, whether it is a ground space landscape environmental art design in the design of building itself or outside the entrance space, should consider combining with the local environment of buildings, roads, public facilities, landscaping etc.; on the other hand, the public space elements, such as buildings, sketch, greening design coordination unified, in order to reflect the visual appearance of the. Through the effective review system, the public also reacts to the design and creation of the artist or the team, so as to truly embody the publicity and aesthetic nature of public space art design.

Regional Characteristics. Most cities in our country have a profound historical background, rich geographical environment and colorful folk culture, the involvement of public art in the subway space can play a role in adding fuel to the flames. The public will have a dialogue with the city culture and history, and will choose to visit the museum and art gallery regularly. The involvement of public art in the subway space creates a very convenient and colorful environment for them. However, in our country there are still a lot of city subway adopts modularization design, the use of materials and design methods are very similar, the same, the city cultural and geographical features is not accurate enough, lack of distinctive features. The combination of geographical features design a unique station building, strengthening its external image and space characteristics, so that people can form a clear impression, make the visual focus, strengthen the identification of the station; design conditions, avoid monotony in the form of space form reflected in the style of unity at the same time, the station should highlight the distinctive the characteristics of. China in the field of design creation has been uneven in quality. The majority of utilitarianism in concept, there is no deep research on Chinese traditional culture, just stay in the China element of this plain surface. Chinese culture represents a kind of spirit, only into the minds of the people, in order to establish the correct direction of public space in the subway. On the one hand, the public space environmental art design should be coordinated with the surrounding environment of the city, to maintain integrity and unity of area space and local characteristics; on the other hand, the regional culture in design art in public space station environment, create high-quality public space with cultural and artistic taste. So, into the regional characteristics of the design concept to improve the image of the city and charm, city culture has a positive effect. The station design should be the architectural features of the geographical location and landscape integration increase the recognition features around the station area, create a unified and comprehensive sense of place and geographical sense so that people understand the site's location. 


\section{Key Points of Art Design of Different Parts in Public Space of Rail Transit}

Ceiling Art Design. In the urban rail transit environment, the most sensitive part of the design is the ceiling of the sense of space. The decorative ceiling generally dominated by modern elements, part of the national characteristics of the rich culture of the area can use the rich local cultural characteristics of the elements of the decoration, but also can use gravity, add some three-dimensional decorative ceiling, enhance the interest of space. There are public art works, large lighting facilities need to focus on shaping the space in the set, or to highlight the theme imagery of the station, can use different decoration materials, color, or completely change form means rich region of the ceiling, focus on the performance of the design theme through this method, can strengthen the overall sense of design and performance the space station, decoration level clear, more artistic and visual effects. In accordance with the requirements of the rail transit station building function, must be on the ceiling lighting, air conditioning and air placement, guide signs and other equipment, to meet the functional requirements at the same time, a comprehensive optimization of the combination of all equipment and pipeline installed on the ceiling, the station space can leave enough height to create conditions for the space environment the art of shaping. The ceiling can be combined with the spatial features of the different level of scattered changes, and lighting set point line surface of different forms of combination, simple design is not superfluous decoration space sequence and strengthen the sense of vision, not only to the limited space and direction. At the same time, along with the change of the ceiling nature. The overall decoration effects all blend into one harmonious whole station space, both functional and decorative significance.

Wall Art Design. People usually stay in the visual center of straight line, the walls become easy to notice where most passengers. Therefore, the interior wall design of rail transit station is very important. The station interior wall decoration are often able to play the dissemination of information, improve the spatial scale, to create a comfortable atmosphere, the general use of wall texture, color, shape, pattern, texture and other diversified processing and art design in the design, to create a different style of decoration, rich sense of space, raising awareness of space. Wall design should pay attention to the geographical and cultural landscape resources, and combined with regional cultural design. In order to avoid too many people gather to watch, wall decoration design content should be concise summary. Wall is the focus of the design of rail transit space, because the wall is the most common place for travelers eyes, but also easy to impress the minds of passengers. The wall design is divided into two kinds, one is the static design, art design, space layout of rail corridor wall, the other is a dynamic design, according to the running speed of the trains in this design, stitching through numerous repeating patterns on the wall to achieve static and dynamic basis. The modern subway station walls created a lot of works of art, but most of the use of marble and other materials, are generally single form, with frescoes mainly lack of change, the public art mostly old, color is dark, there is no good to decorate and beautify the indoor space, failed to develop a space environment quality. While different forms considering the spatial characteristics and limitations of different functional areas, stairs, escalator space for passengers to quickly access the area itself is limited to the design of the pillars, therefore, the region wall treatment using a simple art form, and spatial characteristics of the entrance and the hall layer determines the form of rich wall design complex.

Floor Art Design. The ground pavement is the interface with the highest frequency of physiological, psychological and visual contact, which has great influence on the quality of the space. With the development of city construction and the improvement of people's aesthetic consciousness, pavement design and pavement technology of rail transit station of traditional public space cannot meet the requirements of modern subway station public space decoration design, the general lack of humanization and individuation, therefore, need to introduce the concept of pavement landscape to improve the space environment, to better meet the needs of pedestrians pass. The use of various types of pavement materials and construction techniques of the direct and effective means to the ground with rich colors, diverse forms and characteristics of the texture, with symbolic detail design itself constitutes a landscape space, giving the vitality and personality. Rail transit station interior space design should first meet the basic functional requirements, hard ware, corrosion resistance, moisture, 
fire, surface smoothness, gloss, non-slip. Secondly, the combination of practical functions and decorative features to enhance the artistic expression of pavement design rich visual effects of space. The most practical in orbit space is the laying of the ground. Good ground laying design can be reflected in the humanities on the various groups of thoughtful care; to ensure the safety of the road on the road to avoid the possibility of falling. In psychology, through the color and other aspects of the suggestion for passengers to provide a safe and secure psychological experience; in the visual and other elements of the space as well as their own harmony, beauty. At the same time, a good ground laying design is also the guarantee of passengers through the order.

\section{Conclusion}

With the social and economic rapid development, the construction of the urban rail traffic in the big cities in China is in full swing. The art design of public space in the urban rail traffic not only reflects the grade and image of the city, but also explores the art design of public space. It is hoped that this study can enrich the knowledge of the art design of the public space in rail transit stations and provide some effective references for the follow-up research.

\section{References}

[1] Yan Baoping. Research on Dynamic Generation of 3D Lines in City Rail Transit Simulation System [J]. Journal of System Simulation, 2016, 28(10): 2607-2612.

[2] Wang Shufen, Ren Jie. Study on the Impact of Elevated Rail Traffic on the Urban Landscape and the Response Measures [J]. China Exploration \& Design, 2011(2):57-60.

[3] Yang Peiyun. For the Investigation of the Public Indoor Space Design in Urban Rail Transit [J]. Design, 2015(21): 111-113.

[4] He Ming, Ji Sisi. The Exploration of Public Device Art in the Transportation Construction-Taking Wuhan Rail Transit Subway Line 2 Art Design Engineering as an Example [J]. Urbanism and Architecture, 2013(20): 223-224. 